\title{
Short-term satiating effect of the fat replacer sucrose polyester (SPE) in man
}

\author{
BY TOINE HULSHOF* AND CEES DE GRAAF† \\ Department of Human Nutrition, Wageningen Agricultural University, P.O. Box 8129, $6700 \mathrm{EV}$ \\ Wageningen, The Netherlands
}

AND JAN A. WESTSTRATE

Unilever Research Laboratorium, Vlaardingen, The Netherlands

(Received 9 May 1994 - Revised 30 January 1995 - Accepted 2 February 1995)

\begin{abstract}
The effects of different amounts of the non-absorbable fat replacer sucrose polyester (SPE), water, and fat added to six warm preload lunches on feelings of appetite and food intake were investigated in two studies that were replicates of each other. In the first study thirty-nine subjects consumed rice preloads; in the second study thirty-five subjects consumed macaroni preloads. The six preloads were fixed on three energy levels: $1.8,2.7$, or $3.7 \mathrm{MJ}$. At $2 \mathrm{~h}$ after preload consumption a test-meal buffet of thirty-one products was presented. Food intake was recorded on the study day, and the day after the study day. For women no energy compensation occurred in either study. Men showed a tendency to compensate for the energy differences between the preloads. However, when the fat of the preloads was replaced by SPE, energy compensation was less than $50 \%$ and non-significant. Statistically significant energy compensation ( $66 \%$ ) was found when fat was replaced by water. No macronutrient-specific compensation occurred in men or women in either study. Lower total fat and energy intakes were found with the preloads where fat was replaced by SPE compared with the preloads containing fat. The appetite ratings were in line with the energy intake values, with no differences in women, and higher appetite ratings after the lower energy preloads in men. This short-term study indicates that SPE may be a useful aid to reduce fat and energy intakes.
\end{abstract}

Sucrose polyester: Energy intake: Appetite

Sucrose polyester (SPE) is a non-energetic fat replacer made from sucrose molecules chemically linked with fatty acids derived from edible oils or fats. SPE has a similar appearance, and the same physical and sensory properties as normal dietary fats, but it is not digested and absorbed in the human body (Fallat et al. 1976). SPE could be a useful substance to reduce the fat and energy contents of food products. One of the major nutritional issues with respect to the replacement of fat by SPE is the question of whether or not this replacement results in a behavioural adaptive response regarding food intake. SPE will only contribute to a reduced fat or energy intake when subjects do not compensate for the energy or fat deficit when fat is replaced by SPE.

Until now only six short-term studies (Blundell et al. 1992; Rolls et al. 1992; Birch et al. 1993; Cotton et al. 1993; Hulshof et al. 1993 a, 1995) and one longer term study (Glueck et al. 1982) of the effect of SPE on feelings of hunger and satiety and subsequent food intake have been performed. Blundell et al. (1992) and Rolls et al. (1992) found complete energy compensation for the energy deficit sustained at breakfast. However, no compensation was found in the lunch test-meal in either study; the compensation occurred in both studies at

* Present address: Kellogg's Benelux, Fountain Plaza, Belgicastraat 7, B-1930 Zaventem, Belgium.

$\uparrow$ For reprints. 
the second test meal ( $7 \mathrm{~h}$ after breakfast) and afterwards in the evening. In the study of Rolls et al. (1992) no consistent differences in appetite ratings were found at any time of the day between the SPE and fat preloads. Birch et al. (1993) investigated the $48 \mathrm{~h}$ food intake of 2-5-year-old children after manipulation of the first three meals of the first day. They reported partial compensation at the end of day 1 and almost complete energy compensation at the end of day 2 . In two studies of Hulshof $e t a l$. $(1993 a, 1995)$ the satiating effect of croissants containing either fat or SPE was investigated. The energy difference of $1.65 \mathrm{MJ}$ between the SPE preload and the fat preload did not result in differences in subsequent energy intake on the study day nor on the day after the study day for either study. Feelings of hunger and satiety were not influenced by the replacement of fat by SPE. Cotton et al. (1993) investigated the effect of replacing $55 \mathrm{~g}$ fat (2.0 MJ) by SPE in two studies. No energy compensation was found in either study, indicating that SPE is as satiating as fat. In the only longer term study with SPE (Glueck et al. 1982) in obese subjects, no energy compensation and no differences in appetite feelings were found. In conclusion, there is no consensus about the effect of the replacement of fat by SPE on subsequent energy intake.

The discrepancies in the results between the studies could be due to the different methodologies used. Blundell et al. (1992) and Rolls et al. (1992) gave a fixed preload at breakfast time followed by two test meals at 12.00 and 16.30 hours, and measured the ad lib. food intake up to and including the breakfast of the next day. Hulshof et al. (1993a) investigated the effect of a fixed quantity of manipulated croissants, consumed at different times of the day (at breakfast, lunch, or during the afternoon), followed by a $210 \mathrm{~min}$ deprivation period, on the ad lib. food intake of days 1 and 2 . In another study of Hulshof et al. (1995) the effect of fixed preload consumption was investigated at lunch-time, followed by three periods of deprivation $(15,135$ and $285 \mathrm{~min})$ on the ad lib. food intake of days 1 and 2. Cotton et al. (1993) investigated the effect of fixed food manipulations on day 1 on the ad lib. food intake of day 2. Birch et al. (1993) investigated the effect of manipulations in the first three meals of day 1 on the ad lib. food intake of days 1 and 2 . In the experiment of Glueck et al. (1982) several food items, which could be consumed during the entire day, were manipulated. Total food intake was measured during $20 \mathrm{~d}$ with and $20 \mathrm{~d}$ without the fat replacer SPE in a crossover design. At present it remains unclear what the effects of the differences in methodology are on the food intake of the subjects, or if there are differences between men and women. The measurement of food intake with test meals is more precise than with food diaries, and therefore probably better for investigating mechanistic aspects of appetite control and food intake regulation. However, it is more difficult to extrapolate the results of a preload test-meal study to a real life situation, compared with a preload ad lib. study.

To obtain more robust results we decided to perform two studies that were replicates of each other, with relatively large numbers of subjects, both men and women, and with a sensitive design (preload test-meal design). In the present study the main goal was to investigate the effects of different doses of fat and SPE on feelings of hunger and satiety and subsequent energy intake. This paper deals with two studies, the second study (with macaroni meals) being a replicate of the first study (with rice meals). As differences in results between men and women were found in the present studies, the effects of the fat and SPE manipulation for both men and women are presented as well.

SUBJECTS AND METHODS

In the present paper two similar studies with a preload test-meal design are presented. As studies on appetite are difficult to replicate between research centres, we felt it necessary to confirm the results of the first study by repeating it within the same research group. This 
Table 1. Characteristics of the participants of the rice-meal and the macaroni-meal studies

(Mean values and standard deviations)

\begin{tabular}{|c|c|c|c|c|c|c|c|c|}
\hline & \multicolumn{4}{|c|}{ Rice meal } & \multicolumn{4}{|c|}{ Macaroni meal } \\
\hline & \multicolumn{2}{|c|}{$\operatorname{Men}(n 16)$} & \multicolumn{2}{|c|}{ Women ( $n$ 23) } & \multicolumn{2}{|c|}{ Men $(n 17)$} & \multicolumn{2}{|c|}{ Women (n 18) } \\
\hline & Mean & SD & Mean & SD & Mean & SD & Mean & $\mathrm{SD}$ \\
\hline Age (years) & 22 & 3 & 23 & 6 & 22 & 2 & 22 & 3 \\
\hline Height (m) & $1 \cdot 84$ & 0.05 & 1.69 & 0.05 & $1 \cdot 84$ & 0.04 & $1 \cdot 71$ & 0.06 \\
\hline Weight (kg) & 69 & 8 & 62 & 8 & $76^{*}$ & 8 & 61 & 6 \\
\hline $\mathrm{BMI}\left(\mathrm{kg} / \mathrm{m}^{2}\right)$ & 20 & 2 & 21 & 2 & $22^{* *}$ & 2 & 21 & 1 \\
\hline Body fat $(\%) \dagger$ & 14 & 4 & 26 & 4 & 16 & 4 & 28 & 3 \\
\hline Restraint score $\neq$ & $1 \cdot 4$ & $0 \cdot 4$ & $2 \cdot 4$ & 0.6 & $1.9 * *$ & 0.4 & $2 \cdot 3$ & 0.6 \\
\hline
\end{tabular}

Mean values were significantly different from those for men consuming the rice meal, ${ }^{*} P<0 \cdot 05,{ }^{* *} P<0 \cdot 01$.

$\uparrow$ Fat mass was calculated by means of biceps plus triceps skinfolds according to the formula of Durnin \& Womersley (1974).

\$ The restraint score was measured with the Dutch eating behaviour questionnaire of van Strien (1986). The minimum value is 1 (no restraint), the maximum value is 5 (high restraint).

replication would increase the generalizability of the results. The second study was a repeat of the first study, except for the subjects and the type of meal. In the first study the subjects consumed a rice meal and in the second the subjects consumed a macaroni meal as a preload at lunch-time. At $2 \mathrm{~h}$ after the preload consumption a buffet-like test meal was presented to the subjects.

\section{Subjects}

Thirty-nine subjects (sixteen male and twenty-three female) participated in the rice study, and thirty-five subjects (seventeen male and eighteen female) participated in the macaroni study. Most subjects were students, had a normal weight, and were not high restraint according to the Dutch eating behaviour questionnaire (DEBQ) of van Strien (1986). All subjects were paid for participation. Table 1 shows the main characteristics of the subjects of both studies.

The subjects were informed that the experiment was meant to investigate the effect of warm meals on hunger and satiety. Some subjects said that they had noticed differences between the different meals, but post-experimental briefing revealed that they did not know how many and which experimental manipulations were given. Before participation all subjects gave their informed consent. Both studies were approved by the Medical Ethical Committee of the Department of Human Nutrition, Wageningen Agricultural University.

\section{Preloads}

The preloads in this study consisted of commercially available deep-frozen meals that only needed to be heated before consumption. These meals were rice goreng (fried rice with meat and vegetables) and macaroni with meat and vegetables (of the brand IGLO options plus (IGLO-OLA B.V., Utrecht, The Netherlands)). These meals contained a small amount of fat ( $30 \mathrm{~g}$ fat $/ \mathrm{kg})$, resulting in $28 \%$ energy from fat.

Six different preloads were given in both the rice and macaroni studies, which only differed in fat and SPE content. The preloads were constructed in such a way that three different series could be investigated. The first one was the SPE series (i.e. water-, SPE/water- and SPE-preloads) with equal energy contents but with different degrees of greasiness between the three preloads. The second series was the fat series (i.e. water-, 
Table 2. Energy content and macronutrient composition of rice-and macaroni-based meals containing added water, sucrose polyester (SPE; fat replacer) and fat in different combinations

\begin{tabular}{|c|c|c|c|c|c|c|c|c|c|c|c|c|}
\hline \multirow[b]{2}{*}{ Preload meal } & \multirow{2}{*}{$\begin{array}{l}\text { Weight } \\
\text { (g) }\end{array}$} & \multicolumn{2}{|c|}{ Energy } & \multicolumn{2}{|c|}{ Fat } & \multicolumn{2}{|c|}{ Protein } & \multicolumn{2}{|c|}{ Carbohydrate } & \multicolumn{2}{|c|}{ SPE } & \multirow{2}{*}{$\begin{array}{c}\text { Added } \\
\text { water } \\
\text { (g) }\end{array}$} \\
\hline & & $(\mathbf{M J})$ & (kcal) & (g) & $(\% \mathrm{E})$ & (g) & $(\% \mathrm{E})$ & (g) & $(\% \mathrm{E})$ & (g) & $(\% \mathrm{E})$ & \\
\hline \multicolumn{13}{|l|}{ Rice-based } \\
\hline SPE & 500 & $1 \cdot 89$ & 446 & 14 & 28 & 23 & 20 & 59 & 52 & 50 & 0 & 0 \\
\hline SPE/water & 500 & 1.89 & 446 & 14 & 28 & 23 & 20 & 59 & 52 & 25 & 0 & 25 \\
\hline Water & 500 & 1.89 & 446 & 14 & 28 & 23 & 20 & 59 & 52 & 0 & 0 & 50 \\
\hline Fat/water & 500 & $2 \cdot 84$ & 671 & 39 & 52 & 23 & 14 & 59 & 35 & 0 & 0 & 25 \\
\hline Fat & 500 & 3.79 & 896 & 64 & 64 & 23 & 10 & 59 & 26 & 0 & 0 & 0 \\
\hline Fat/SPE & 500 & $2 \cdot 84$ & 671 & 39 & 52 & 23 & 14 & 59 & 35 & 25 & 0 & 0 \\
\hline \multicolumn{13}{|c|}{ Macaroni-based } \\
\hline SPE & 450 & 1.69 & 404 & 12 & 27 & 24 & 24 & 50 & 50 & 50 & 0 & 0 \\
\hline SPE/water & 450 & 1.69 & 404 & 12 & 27 & 24 & 24 & 50 & 50 & 25 & 0 & 25 \\
\hline Water & 450 & 1.69 & 404 & 12 & 27 & 24 & 24 & 50 & 50 & 0 & 0 & 50 \\
\hline Fat/water & 450 & $2 \cdot 63$ & 629 & 37 & 53 & 24 & 15 & 50 & 32 & 0 & 0 & 25 \\
\hline Fat & 450 & 3.57 & 854 & 62 & 65 & 24 & 11 & 50 & 23 & 0 & 0 & 0 \\
\hline Fat/SPE & 450 & $2 \cdot 63$ & 629 & 37 & 53 & 24 & 15 & 50 & 32 & 25 & 0 & 0 \\
\hline
\end{tabular}

$\% \mathrm{E}$, percentage of total dietary energy.

fat/water- and fat-preloads) with different energy contents and different degrees of greasiness. The third series was the SPE $\times$ fat series (i.e. SPE-, fat/SPE- and fat-preloads) with different energy contents but with equal degrees of greasiness. In this third series the effects on appetite and energy intake of the fat replacer SPE could be compared directly with the effects of fat.

As weight may act as a confounder on appetite, the addition of fat or SPE to the meals was paralleled by the addition of water, so that within each study all preloads had equal weight. In Table 2 the compositions of the six preloads for both studies are listed.

We were aware that, because each subject received the same preloads, the energy contents of the preloads were relatively large for women and not for men. We expected that if the subjects detected post-ingestive differences between the preloads they would compensate independently of the energy level of the preload.

Before the experiment started it was determined empirically how much water was lost by heating, and how much fat or SPE was left on the plate after consumption of the preload. No differences in water loss were found between the preloads with added fat and the preloads with added water, with an average of $6 \mathrm{~g}$ water loss per preload. For obtaining the desired manipulation, an additional $4 \mathrm{~g}$ fat, SPE, water or a combination of these three substances was added, as this was the amount that remained on the plate after consumption. The SPE was made in one batch for both studies by the Unilever Research Laboratorium (Vlaardingen, The Netherlands) and had a melting range from about 32 to $34^{\circ}$. The fat was commercially available frying fat without protein, water, or flavours added (Albert Heyn, Zaandam, The Netherlands), and was similar to the SPE with regard to melting range, appearance and sensory characteristics.

\section{Test meals}

The test meal was composed of attractive sweet and savoury snacks, fruits, and drinks. Drinks were semi-skimmed milk, full-fat chocolate milk, and orange juice. Fruits comprised apples, oranges and bananas. Sweet snacks included apple pie, chocolate 
confectionery (e.g. Mars and chocolate bars), vanilla custard with cream, fruit yoghurt, cake, and biscuits. Savoury snacks included different meat rolls, soft rolls with ham or cheese, and potato crisps. All test-meal products with their composition are listed in Appendix A. The test meal was presented in a buffet-like manner, and subjects were free to eat as much or as little as they wanted.

\section{Measurements}

Eating behaviour characteristics of the subjects. The DEBQ was used to obtain scores for restrained eating, external eating and emotional eating (van Strien, 1986).

Subjective feelings of hunger and satiety. Six items on hunger and satiety were rated by means of a mark on a $150 \mathrm{~mm}$ visual analogue rating scale. The six items were: appetite for a meal; appetite for something sweet; appetite for something savoury; over-satiety (overfullness); feeble, weak with hunger; appetite for a snack. One each of these terms was placed above the centre of each of the six visual analogue scales, which were anchored on the left and right with the terms 'weak' and 'strong' respectively. Written and oral instructions were provided to the subjects about the meaning of these terms (Hulshof et al. 1993 b). 'Appetite for a meal' refers to appetite for a complete meal, either a hot meal or a sandwich meal, 'Feeble, weak with hunger' reflects a strong urge to eat.

Energy intake. One of the major problems with respect to appetite research is obtaining an objective measurement of the spontaneous food intake of subjects. It would be ideal to weigh everything a subject consumes, but this would interfere very strongly with the person's regular food intake. As there is no gold standard, the best method has to be taken with regard to the research question (Cameron \& van Staveren, 1988).

In the present studies we wanted to investigate the effect of SPE on satiety (not satiation) (Blundell et al. 1992), and therefore we included a deprivation period of $2 \mathrm{~h}$ to avoid appetite ratings and the test-meal intake being influenced by energy intake in between the preload and the test meal. The test meal was given to have a precise measurement of the food intake after the different preloads. After the test meal the ad lib. consumption was measured using food diaries, in order to have a better measure of the subjects' regular food intake when compared with the test-meal food intake (Cameron \& van Staveren, 1988). With the food diaries and the numbers of subjects used we were able to find a difference of about $1 \mathrm{MJ}$ (power 0.90, $P<0.05$ ).

The energy intake at the test meal was calculated using the Dutch food composition tables (NEVO, 1986). Every food product was weighed before consumption, and leftovers were weighed after the test meal to obtain the weight of products consumed per subject.

The energy and nutrient intakes during the remainder of the day were recorded by means of a food diary. Subjects were asked to record all the foods and drinks consumed during the day according to the instruction of the food diary. All the foods and drinks consumed during the warm evening meal had to be weighed to an accuracy of $2 \mathrm{~g}$ on electronic scales (Soehnle scalina; Soehnle-Waagen GMBH \& Co, Murrhardt/Württ, Germany). The weights of the other foods consumed during the day were estimated by means of standard household measures. In the normal Dutch diet, lunch and snack items usually consist of ordinary food items, of which the weight can be accurately estimated by standard household measures. This is usually not the case for the foods and drinks eaten at the warm meal.

The food diaries were checked and coded by experienced dietitians. In cases of unclear food records subjects were asked about these by the dietitians within 1 week. Energy intake was calculated using the Dutch food composition tables (NEVO, 1986).

Sensory perception and pleasantness. Subjects rated the visual attractiveness of the preload meals before preload consumption. Pleasantness and the perceived intensity of the 
Table 3. The visual attractiveness, greasiness, wateriness and pleasantness of rice- and macaroni-based meals containing added water, sucrose polyester (SPE; fat replacer) and fat in different combinations*

(Values were determined on a scale from 0 (weak) to 150 (strong) $\mathrm{mm}$ )

\begin{tabular}{|c|c|c|c|c|c|c|}
\hline Preload meal... & SPE & SPE/water & Water & Fat/water & Fat & Fat/SPE \\
\hline \multicolumn{7}{|l|}{ Rice meal (n 39) } \\
\hline Visual attractiveness & $87^{a}$ & $89^{a}$ & $82^{a}$ & $86^{\mathrm{a}}$ & $89^{\mathrm{a}}$ & $85^{\mathrm{a}}$ \\
\hline Greasiness & $123^{\mathrm{a}}$ & $102^{b}$ & 44 & 81 & $109^{b c}$ & $116^{\mathrm{ac}}$ \\
\hline Wateriness & $61^{\mathrm{ab}}$ & $79^{\mathrm{cf}}$ & $95^{\text {ef }}$ & $94^{\mathrm{de}}$ & $77^{\mathrm{cd}}$ & $67^{\mathrm{ac}}$ \\
\hline Pleasantness & $67^{\mathrm{a}}$ & $83^{\mathrm{ab}}$ & $89^{b}$ & $76^{\mathrm{ab}}$ & $84^{\mathrm{b}}$ & $76^{\mathrm{ab}}$ \\
\hline \multicolumn{7}{|l|}{ Macaroni meal ( $n$ 35) } \\
\hline Visual attractiveness & $57^{a}$ & $71^{\mathrm{ab}}$ & $85^{b}$ & $70^{\mathrm{ab}}$ & $67^{a b}$ & $70^{\mathrm{a}}$ \\
\hline Greasiness & $134^{\mathrm{a}}$ & $112^{b}$ & 51 & 80 & $116^{\mathrm{bc}}$ & $126^{\mathrm{ac}}$ \\
\hline Wateriness & $50^{\mathrm{a}}$ & $62^{a b}$ & $80^{\text {be }}$ & $75^{\mathrm{be}}$ & $77^{\mathrm{h}}$ & $58^{\mathrm{ac}}$ \\
\hline Pleasantness & 58 & $75^{\mathrm{a}}$ & $105^{\mathrm{b}}$ & $95^{\text {be }}$ & $80^{\mathrm{aed}}$ & $74^{\mathrm{ad}}$ \\
\hline
\end{tabular}

a, b,c, d Mean values within a row with unlike superscript letters were significantly different, $P<0.05$.

* The attributes that had significantly different ratings between the six preloads are presented in this table (all $P<0 \cdot 01$ ). Only the visual attractiveness ratings of the rice study did not differ between the six preloads.

preloads were rated according to seven attributes during and after consumption of the preload meals. The seven attributes were: sweetness, saltiness, sourness, bitterness, greasiness, crispness and wateriness. Ratings were made on $150 \mathrm{~mm}$ visual analogue rating scales. No significant differences were found for the four basic tastes. The relevant differences in sensory attributes are shown in Table 3.

\section{Procedure}

The six different preloads per study were offered in a random sequence that varied for each subject. Every subject received each preload on a different day, resulting in a withinsubjects repeated measures design. Study days were always on Tuesdays and Thursdays to eliminate weekend effects. A test day was run before the first study day to familiarize the subjects with all the procedures of the experiment. The rice study was done in April 1992 and the macaroni study in May 1992, in a 4-week period for each experiment.

Subjects were asked not to eat or drink anything except water after 23.00 hours the previous evening. Before the study started each subject had to write down what he or she wanted to eat every morning before preload consumption at lunch-time, and this was discussed with the dietitian. Subjects were instructed to consume exactly the same foods and drinks until the preload consumption on every test day. They consumed the preload lunch in the departmental dining room at 12.30 hours.

Fig. 1 is a flow diagram showing timing and points of appetite assessments. During the $2 \mathrm{~h}$ deprivation period between the preload meal and the test meal the subjects were not allowed to eat or drink anything except water. This was done to enable the temporal tracking of motivational ratings for this period without interference of energy consumption. After these $2 \mathrm{~h}$ the subjects composed and consumed their test meal from a buffet at 14.30 hours. They were instructed to eat as little or as much as they wanted. After the buffet test meal the subjects had to record the foods and drinks they consumed on the study day (day 1) and the day after the study day (day 2) in a food diary. Appetite ratings were recorded just before (12.30 hours) and just after (12.45 hours) the consumption of the preload, at 13.00 hours, at 14.00 hours, and just before the test-meal consumption (14.30 hours). 


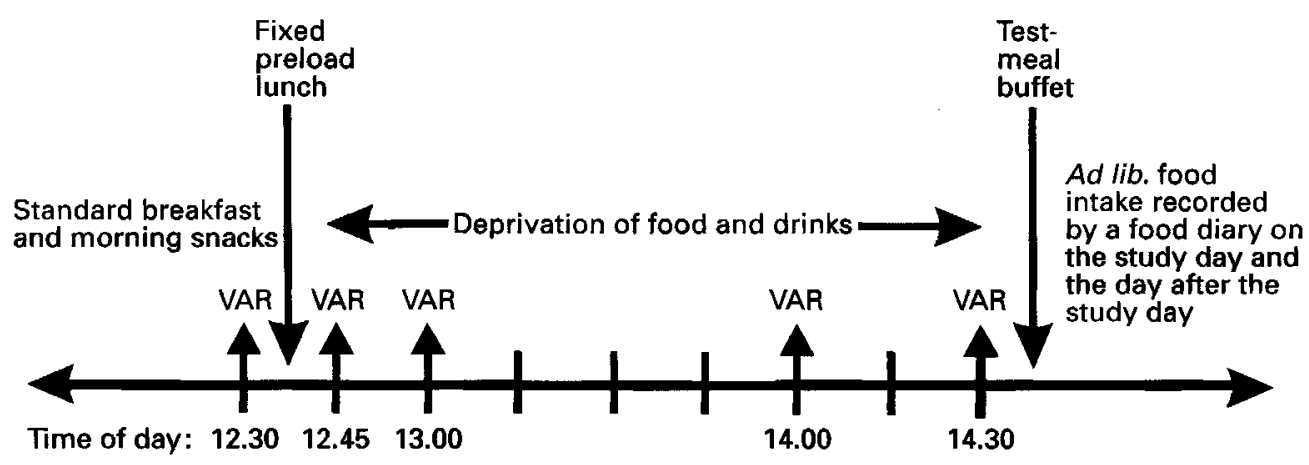

Fig. 1. Flow diagram showing the structure of the present study with the timings of the different actions and measurements. Visual analogue ratings (VAR) were collected regularly to assess the subjects' appetite feelings.

\section{Data analysis}

Ratings of hunger and satiety scores were read by an optical mark reader, and converted into scores from 1 (weak) to 25 (strong). In the present paper only the results for 'appetite for a meal' are discussed as this is conceived as being similar to general appetite (de Graaf et al. 1992).

To enable one overall comparison of the effects of the six different preloads on 'appetite for a meal', the area under the curve (AUC) was taken as the dependent variable (instead of the five scores on motivational ratings). One advantage of the AUC is that it gives one value, so that the effects of preloads can be compared directly with each other (instead of comparing curves). Another advantage is that this measure takes into account the magnitude of the different time intervals between the adjacent measurements (which is not the case for ANOVA with the absolute values). The disadvantage of this analysis is that the temporal tracking of the hunger and satiety feelings is missed (Hulshof et al. 1993 b).

The AUC was calculated as a percentage of the total area (AUC\%) by the following equation (see Fig. 2):

$$
\begin{gathered}
(((0 \cdot 25((B-A) / 2+A)+0 \cdot 25((C-B) / 2+B)+((D-C) / 2+C) \\
+0 \cdot 50((\mathrm{E}-\mathrm{D}) / 2+\mathrm{D}))-2) / 48) \times 100 \Leftrightarrow(((1 / 8(\mathrm{~A}+2 \mathrm{~B}+5 \mathrm{C}+6 \mathrm{D}+2 \mathrm{E}))-2) / 48) \times 100,
\end{gathered}
$$

where $\mathrm{A}, \mathrm{B}, \mathrm{C}, \mathrm{D}$ and $\mathrm{E}$, are the motivational ratings at $0,0.25,0.50,1,1.50$ and $2 \mathrm{~h}$ respectively. The lower the AUC\% value for 'appetite for a meal', the more satiating the preload is.

Statistical analysis for the effects of the preloads on AUC \% and food intake were carried out with ANOVA for repeated measures using the SAS statistical software package (Statistical Analysis Systems, 1990), with the type of preload as the fixed within-subject factor, and the subjects as the random factor.

Percentages of energy for the macronutrients were calculated using the mean of the individual values. To investigate whether there was a dose-response effect for the different energy levels of the preloads, regression coefficients were calculated for each individual for the fat-series (i.e. the water-, water/fat- and fat-preloads) and the SPE $\times$ fat-series (i.e. the SPE-, SPE/fat- and fat-preloads). The negative value of the slope of the regression equation gives the satiating efficiency as described by Kissileff (1984). If the mean of the individual regression coefficients was statistically significantly different from zero then this would indicate energy compensation. As energy compensation was expected to be in one direction 


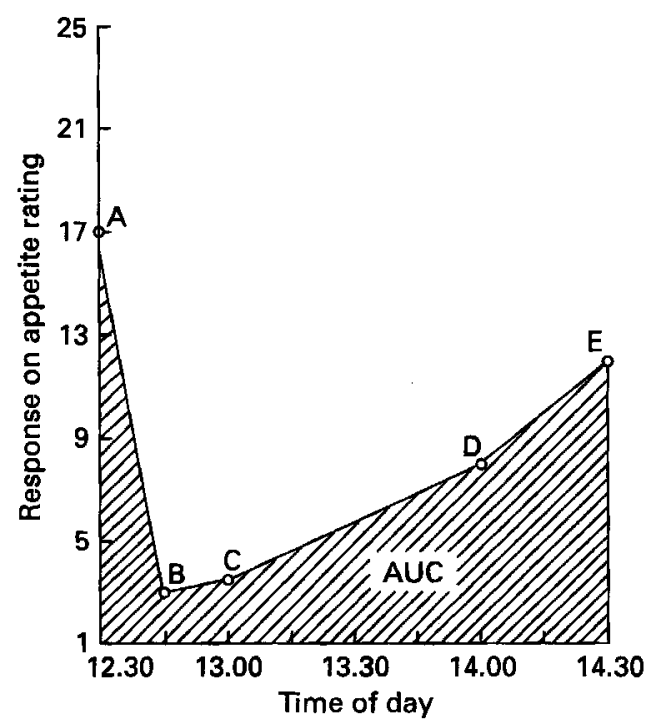

Fig. 2. Illustration of the calculation of the area under the curve (AUC\%), using absolute appetite values. The AUC \% is calculated as the surface under the curve $((1 / 8(A+2 B+5 C+6 D+2 E))$ minus the area between 0 and 1 (time $(14 \cdot 30-12 \cdot 30$ hours $) \times$ appetite $(1-0)=2)$ divided by the total area (time $(14.30-12.30$ hours $) \times$ appetite $(25-1)=48)$ and multiplied by 100 . The result gives the AUC as a percentage of the total area (AUC\%). A lower AUC \% indicates a stronger suppression of appetite than a higher AUC \%.

(i.e. negative slopes and thus positive energy compensation), one-sided $t$ tests were performed. A probability of $5 \%$ was set as the criterion for statistical significance, for all statistical tests.

\section{RESULTS}

Study 1: the rice meals

Feelings of 'appetite for a meal'. Fig. 3 shows the AUC for 'appetite for a meal' ratings from just before preload consumption to just before test-meal consumption as a percentage of the maximum area (AUC\%) for men and women. The effect of preload was statistically significant for men $(F(5,75) 3 \cdot 88, P=0.004)$, but not for women $(F(5,110) 0.57, P=0.72)$. In men higher 'appetite for a meal' ratings were found after the three lower energy preloads (i.e. SPE-, SPE/water-, water-preload) compared with the fat/water- and the fat-preloads. The water-preload also resulted in higher ratings than the fat/SPE-preload (all $F(1,15)>4.73$, all $P<0.05$ ).

Energy intake and energy compensation. The mean energy intake at the test-meal buffet, the total of day 1 (without and with the preload energy), and the total of day 2, as a function of the six preloads for the men and women of the rice study are shown in Table 4. No statistically significant differences were found for the energy intake at the test meal, day 1 (without preload energy) or day 2.

When the total energy intake of day 1 was regarded (with preload energy), significant differences were found for women, with higher intakes with the higher energy preloads and lower intakes with the lower energy preloads. These differences in total energy intakes suggest that no energy compensation occurred, and that the differences were primarily due to the different energy levels of the preloads.

In men a similar pattern was found for the total energy intake of day 1 (with preload energy), with higher intakes with the higher energy preloads and vice versa. The differences 


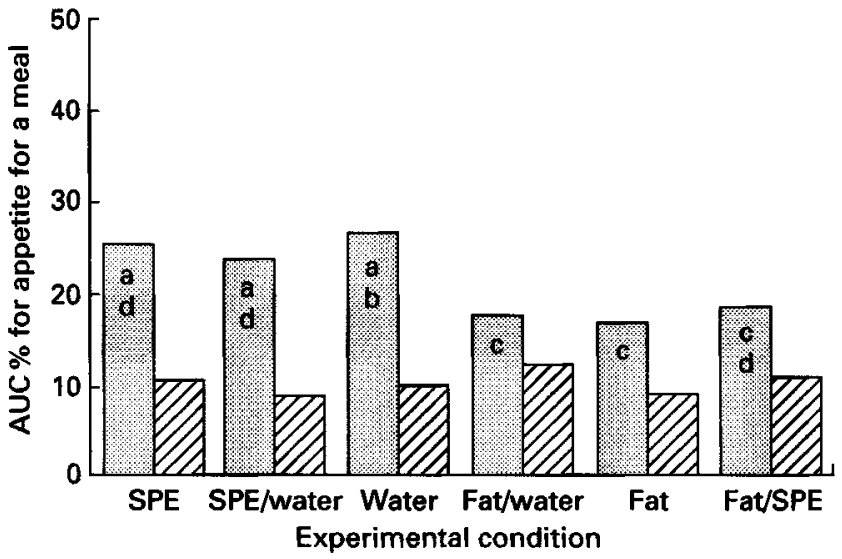

Fig. 3. Mean area under the curve (AUC\%) values, expressed as a percentage of the maximum area, for 'appetite for a meal' following consumption of a rice-based preload meal containing added water, sucrose polyester (SPE;

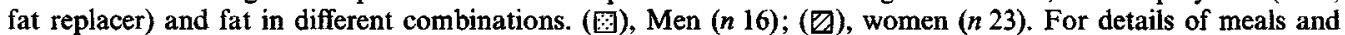
procedures, see Table 2 and pp. 570-576. a,b,e,d Columns not sharing a common superscript letter were significantly different, $P<0.05$.

Table 4. Energy intake (EI; MJ) at the test meal, during day 1 (without and with preload energy) and during day 2 following consumption of a rice-based preload meal containing added water, sucrose polyester (SPE; fat replacer) and fat in different combinations*

(Mean values for sixteen men and twenty-three women)

\begin{tabular}{|c|c|c|c|c|c|c|c|}
\hline $\begin{array}{l}\text { Preload meal... } \\
\text { Energy content ... }\end{array}$ & $\begin{array}{c}\text { SPE } \\
1.9 \mathrm{MJ}\end{array}$ & $\begin{array}{c}\text { SPE/water } \\
1.9 \mathrm{MJ}\end{array}$ & $\begin{array}{c}\text { Water } \\
1.9 \mathrm{MJ}\end{array}$ & $\begin{array}{c}\text { Fat/water } \\
2.8 \mathrm{MJ}\end{array}$ & $\begin{array}{c}\text { Fat } \\
3.8 \mathrm{MJ}\end{array}$ & $\begin{array}{c}\text { Fat/SPE } \\
2.8 \mathrm{MJ}\end{array}$ & ANOVA \\
\hline \multicolumn{8}{|l|}{ EI in test meal: } \\
\hline Men & $5 \cdot 0$ & $4 \cdot 7$ & $4 \cdot 8$ & $4 \cdot 4$ & $4 \cdot 8$ & $4 \cdot 7$ & $F(5,75) 0.31, P=0.9$ \\
\hline Women & $2 \cdot 8$ & $2 \cdot 6$ & $2 \cdot 7$ & $2 \cdot 6$ & 30 & $2 \cdot 3$ & $F(5,110) 0.88, P=0.5$ \\
\hline \multicolumn{8}{|l|}{$\begin{array}{l}\text { El day } 1 \text { without } \\
\text { preload: }\end{array}$} \\
\hline Men & $12 \cdot 4$ & $12 \cdot 1$ & $12 \cdot 6$ & $12 \cdot 2$ & $11 \cdot 6$ & $12 \cdot 1$ & $F(5,75) 0.41, P=0.8$ \\
\hline Women & $8 \cdot 1$ & $7 \cdot 9$ & $8 \cdot 0$ & $8 \cdot 4$ & $8 \cdot 5$ & $7 \cdot 7$ & $F(5,110) 0.78, P=0.6$ \\
\hline \multicolumn{8}{|l|}{ Total EI day 1: } \\
\hline Men & $14 \cdot 3$ & $14 \cdot 0$ & $14 \cdot 5$ & $15 \cdot 0$ & $15 \cdot 4$ & $15 \cdot 0$ & $F(5,75) 1 \cdot 14, P=0.4$ \\
\hline Women & 9.9 & 9.8 & 9.9 & $11 \cdot 2$ & $12 \cdot 3$ & $10 \cdot 6$ & $F(5,110) 8.43, P<0.001$ \\
\hline \multicolumn{8}{|l|}{ Total EI day 2: } \\
\hline Men & $11 \cdot 1$ & $11 \cdot 1$ & $11 \cdot 4$ & $10 \cdot 9$ & $11 \cdot 8$ & $10 \cdot 3$ & $F(5,75) 0.63, P=0.7$ \\
\hline Women & $9 \cdot 1$ & $9 \cdot 0$ & $9 \cdot 1$ & $9 \cdot 3$ & 9.8 & $9 \cdot 4$ & $F(5,110) 0.49, P=0.8$ \\
\hline
\end{tabular}

* For details of meals and procedures, see Table 2 and pp. 570-576.

in total energy intake on day 1 were smaller than the fixed energy differences of the preloads, and were not statistically significant. This could indicate that some energy compensation occurred in men.

The means of the individual regression equations between the energy levels of the preloads and the energy intake on day 1 after the preloads for men and women of the rice study are shown in the left panel of Fig. 4, for both the fat-series (i.e. the water-, water/fat-, and fat-preloads) and the SPE $\times$ fat-series (i.e. the SPE-, SPE/fat- and fat-preloads). For 


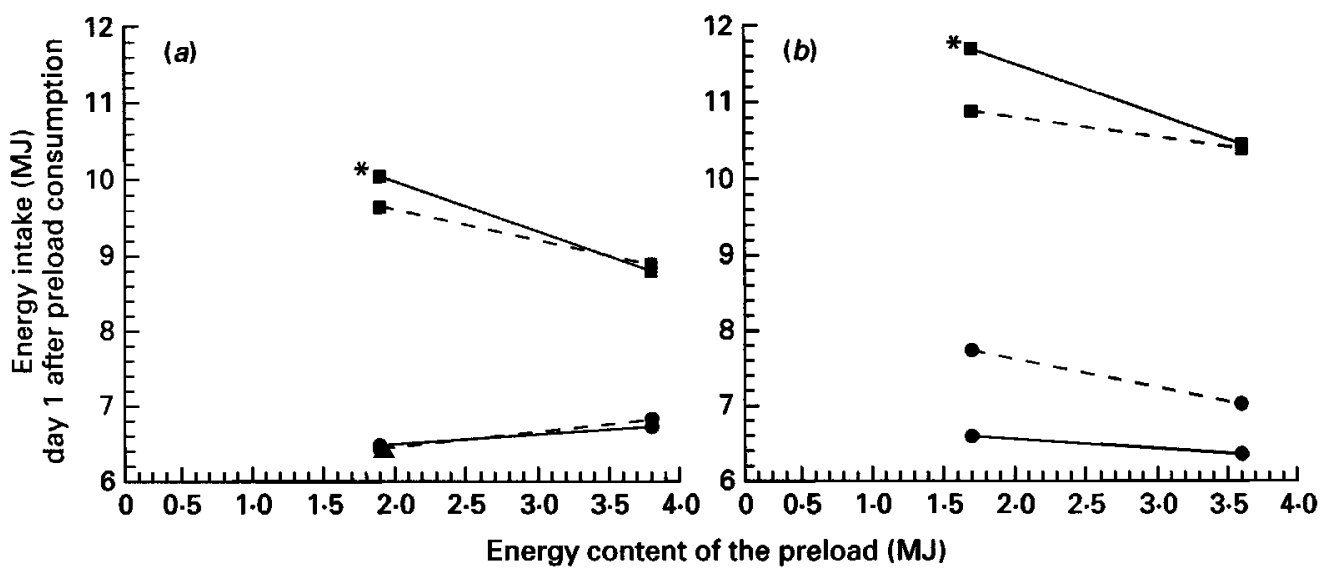

Fig. 4. Means of individual regression equations of energy content of preload (dependent variable) $v$. energy intake after the preload on day 1 (independent variable) for $(a)$ the rice-based preload and $(b)$ the macaroni-based preload. The regression equations for the fat-series (-) were calculated using the water-, fat/water- and fatpreloads, and those for the sucrose polyester (SPE) $\times$ fat-series (-- ) were calculated using the SPE-, fat $/ \mathrm{SPE}$-, and fat-preloads. ( $\square$ ), Men; $(\boldsymbol{O})$, women. ${ }^{*}$ Mean regression coefficients were significantly different from zero $(P<0.05)$. For details of meals and procedures, see Table 2 and pp. $570-576$.

women of the rice study the regression coefficients were positive, with $0.14(P=0.30)$ and $0 \cdot 21(P=0 \cdot 19)$ for the fat- and SPE $\times$ fat series respectively. For men, statistically significant regression coefficients were found for the fat-series, with $-0.67(P=0.02)$, but not for the SPE $\times$ fat-series, with $-0.41(P=0 \cdot 11)$.

Macronutrient intake. When the macronutrient intake on the study day was regarded without the macronutrient intake of the preload, no statistically significant differences in macronutrient intake (as a percentage of energy) were found between the six different experimental conditions in men (all $F(5,75)<2.23$, all $P>0.06$ ) or women (all $F(5,110)<1 \cdot 91$, all $P>0 \cdot 10$ ). This suggests that no macronutrient-specific compensation occurred. On the study day (without preload intake values) men consumed on average 118 (SD 40) g fat, 84 (SD 27) g protein, 358 (SD 80) g carbohydrate and 11 (SD 16) g alcohol, whereas the women consumed on average 74 (SD 30) g fat, 59 (SD 17) g protein, 251 (SD 60) $\mathrm{g}$ carbohydrate and 5 (SD 12) g alcohol.

\section{Study 2: the macaroni meals}

Feelings of 'appetite for a meal'. Fig. 5 shows the AUC for the 'appetite for a meal' ratings as a percentage of the maximum area (AUC\%) for men and women of the macaroni study. There were no statistically significant differences between the six experimental conditions for the AUC \% values of 'appetite for a meal' for men $(F(5,80) 1 \cdot 71, P=0 \cdot 14)$ or women $(F(5,85) 0.98, P=0.43)$. In men, however, a similar pattern for the AUC \% results as in the rice study was found, with higher appetite ratings after the lower energy preloads and lower ratings after the higher energy preloads.

Energy intake and energy compensation. The mean energy intake as a function of the six experimental conditions at the test-meal buffet, the total of day 1 (without and with preload values) and the total of day 2 for the men and women of the macaroni study are shown in Table 5. For women no differences between the six different preloads were found in energy intake at the test meal, for the energy intake of day 1 (without preload energy) or the total energy intake of day 2 . The total energy intake of day 1 (including the preload energy) was significantly different, with higher energy intakes with the higher energy preloads. These 


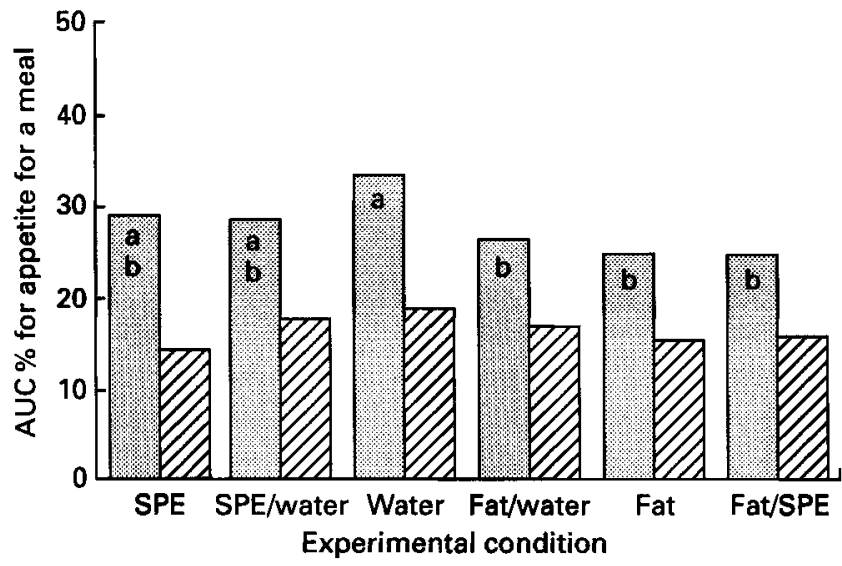

Fig. 5. Mean area under the curve (AUC\%) values, expressed as a percentage of the maximum area, for 'appetite for a meal' following consumption of a macaroni-based preload meal containing added water, sucrose polyester (SPE; fat replacer) and fat in different combinations. ( $)$, Men ( $n$ 17); ( $\oslash)$, women $(n 18)$. For details of meals and procedures, see Table 2 and pp. 570-576. ${ }^{\text {a, }}$ Columns not sharing a common superscript letter were significantly different, $P<0.05$.

Table 5. Energy intake $(E I ; M J)$ at the test meal, during day 1 (without and with preload energy), and during day 2 following consumption of a macaroni-based preload meal containing added water, sucrose polyester (SPE; fat replacer) and fat in different combinations*

(Mean values for seventeen men and eighteen women)

\begin{tabular}{|c|c|c|c|c|c|c|c|}
\hline $\begin{array}{l}\text { Preload meal ... } \\
\text { Energy content ... }\end{array}$ & $\begin{array}{c}\text { SPE } \\
1.7 \mathrm{MJ}\end{array}$ & $\begin{array}{c}\text { SPE/water } \\
1.7 \mathrm{MJ}\end{array}$ & $\begin{array}{l}\text { Water } \\
1.7 \mathrm{MJ}\end{array}$ & $\begin{array}{c}\text { Fat/water } \\
2.6 \mathrm{MJ}\end{array}$ & $\begin{array}{c}\text { Fat } \\
3 \cdot 6 \mathrm{MJ}\end{array}$ & $\begin{array}{c}\text { Fat/SPE } \\
2.6 \mathrm{MJ}\end{array}$ & ANOVA \\
\hline \multicolumn{8}{|l|}{ EI in test meal: } \\
\hline Men & 6.6 & $7 \cdot 2$ & $6 \cdot 9$ & 6.7 & $5 \cdot 6$ & $5 \cdot 9$ & $F(5,80) 4.34, P=0.002$ \\
\hline Women & $3 \cdot 2$ & 2.9 & $3 \cdot 0$ & $3 \cdot 0$ & $3 \cdot 0$ & $2 \cdot 6$ & $F(5,85) 0.41, P=0.8$ \\
\hline \multicolumn{8}{|l|}{$\begin{array}{l}\text { EI day } 1 \text { without } \\
\text { preload: }\end{array}$} \\
\hline Men & $13 \cdot 1$ & $14 \cdot 3$ & $13 \cdot 7$ & $14 \cdot 2$ & $12 \cdot 5$ & $13 \cdot 9$ & $F(5,80) 2 \cdot 29, P=0.053$ \\
\hline Women & 9.7 & $8 \cdot 7$ & $8 \cdot 8$ & $8 \cdot 7$ & $9 \cdot 1$ & $8 \cdot 5$ & $F(5,85) 0.72, P=0.6$ \\
\hline \multicolumn{8}{|l|}{ Total EI day 1: } \\
\hline Men & $14 \cdot 8$ & $16 \cdot 0$ & $15 \cdot 4$ & 16.8 & $16 \cdot 0$ & $16 \cdot 5$ & $F(5,80) 2.47, P=0.04$ \\
\hline Women & $11 \cdot 3$ & $10 \cdot 4$ & $10 \cdot 5$ & $11 \cdot 3$ & $12 \cdot 6$ & $11 \cdot 2$ & $F(5,85) 2.89, P=0.02$ \\
\hline \multicolumn{8}{|l|}{ Total EI day 2: } \\
\hline Men & $12 \cdot 4$ & $13 \cdot 0$ & $12 \cdot 8$ & $12 \cdot 1$ & $11 \cdot 6$ & $11 \cdot 5$ & $F(5,80) 1 \cdot 05, P=0.4$ \\
\hline Women & $9 \cdot 3$ & $9 \cdot 2$ & $8 \cdot 5$ & $9 \cdot 2$ & $8 \cdot 1$ & $8 \cdot 8$ & $F(5,85) 1 \cdot 06, P=0.4$ \\
\hline
\end{tabular}

* For details of meals and procedures, see Table 2 and pp. 570-576.

differences seemed to be due to the different energy values of the preloads. As in the rice study, there was no indication (in either the fat-series or SPE $\times$ fat-series) that women regulated their energy intake according to the energy levels of the preloads.

In men significant differences in energy intake were found between the six preloads at the test meal, and for the total energy intake of day 1 (with preload energy). For the energy intake at the test meal a dose-response reaction could be observed with regard to the energy levels of the preloads of the fat-series $(6 \cdot 9,6 \cdot 7$ and 5.6 MJ after the water-, fat/water- and the fat-preloads respectively), with lower subsequent energy intakes after higher energy 
preloads $(F(2,32) 5 \cdot 37, P=0 \cdot 01)$. A similar dose-response effect was found at the test meal with regard to the preloads of the SPE $\times$ fat series (6.6, 5.9 and 5.6 MJ after the SPE-, fat/SPE-, and fat-preloads respectively) $(F(2,32) 2 \cdot 32, P=0.07)$. At day 2 no statistically significant differences in energy intake were found for men.

The means of the individual regression equations between the energy levels of the preloads and the energy intake on day 1 after the preloads for men and women of the macaroni study are shown in the right panel of Fig. 4, for both the fat-series (i.e. the water, water/fat-, and fat-preloads) and the SPE $\times$ fat-series (i.e. the SPE-, SPE/fat- and fatpreloads). For women the regression coefficients were not statistically different from zero, with $-0.12(P=0.37)$ and $-0.37(P=0.15)$ for the fat- and SPE $\times$ fat-series respectively. For men the regression coefficients were statistically different from zero for the fat-series, with $-0.65(P=0.03)$, but not for the SPE $\times$ fat-series, with $-0.26(P=0.21)$.

Macronutrient intake. No statistically significant differences in macronutrient intake on day 1 without the preload values (as a percentage of energy) were found between the six different experimental conditions in men (all $F(5,80)<0.46$, all $P>0.8$ ) or women (all $F(5,110)<2 \cdot 25$, all $P>0.06$ ). On day 1 men consumed (without preload values) on average 131 (SD 43) g fat, 90 (SD 26) g protein, 412 (SD 91) g carbohydrate and 10 (SD 17) g alcohol, whereas women consumed on average 78 (SD 36) g fat, 63 (SD 21) g protein, 285 (SD 72) g carbohydrate and 5 (SD 10) g alcohol.

\section{GENERAL DISCUSSION}

The two present short-term studies, which were replicates, yielded similar results with respect to energy intake and appetite. Both studies showed that the addition of about $50 \mathrm{~g}$ water, fat or SPE to a warm lunch resulted in some differences in subsequent energy and macronutrient intakes for men, but not for women. Women consumed similar amounts of food, independent of the preload they got. For men significant differences were found in energy intake between the six preloads. Significant energy compensation was found in the fat-series but not in the SPE $\times$ fat-series. No macronutrient-specific compensation was found in either study. With respect to feelings of appetite, small but significant differences were found for men, with higher appetite ratings after the lower energy preloads, whereas in women no differences were found. The differences in appetite were in line with the differences found in the energy intake.

\section{Feelings of 'appetite for a meal'}

Similar patterns in 'appetite for a meal' were observed in men and women in both studies, although the differences in men in the rice study were more pronounced than those in the macaroni study. For women no differences in appetite were found between the preloads. It could be argued that these results were due to a floor effect, which means that all six preloads reduced the women's appetite near to $0 \%$, with the result that, even after the least satiating preload, the bottom of the scale was reached. The response for another appetite dimension ('oversatiety (overfullness)'), which is inversely related to 'appetite for a meal' ratings, showed no statistically significant differences between the six preloads in either study $(P>0 \cdot 16)$. For 'oversatiety (overfullness)' the floor effect was therefore not in question as the average AUC \% values were far away from $100 \%$, being 24 and $44 \%$ for the women of the rice and macaroni studies respectively. This suggests that the absence of differences in 'appetite for a meal' ratings was not due to a floor effect.

It should be noticed that a difference of $1.9 \mathrm{MJ}(450 \mathrm{kcal})$ in energy intake, which constitutes about $20 \%$ of the normal daily intake, resulted in relatively small differences in appetite. The differences in AUC \% between the fat- and water-preloads were on average 
$9 \%$ in men and only $2 \%$ in women. This small effect is in line with the results of other studies with fat and SPE (Rolls et al. 1992; Hulshof et al. 1993a, 1995).

In both studies the appetite ratings seemed to be in line with the subsequent energy intake at the test meal with higher energy intakes after higher appetite ratings.

\section{Energy intake and energy compensation}

In the present study no effects of the preloads on subsequent energy intake were found in women. They consumed similar amounts of energy on days 1 and 2 independent of the experimental manipulation. In neither of the two series where the preloads had different energy levels, (fat-series, SPE $\times$ fat-series) was there an effect of the energy level of the preload on subsequent energy intake. In women, mean energy compensation values were between -21 and $37 \%$ (NS) of the energy differences between the preloads.

In men there were some differences in subsequent energy intake between the different experimental conditions. This seemed to be due to energy compensation. In the present study the energy compensation could be found by taking the negative value of the slope, which was called the satiating efficiency by Kissileff (1984). A slope of -1 means that there is complete $(100 \%)$ energy compensation, whereas a slope of 0 means no $(0 \%)$ energy compensation. For men the regression coefficients of day 1 were significantly different from zero for the fat-series but not for the SPE $\times$ fat-series. For the fat-series the mean energy compensation was similar for the rice and macaroni studies, being 67 and $65 \%$ respectively. For the SPE $\times$ fat-series these values were lower at 41 and $26 \%$ energy compensation (NS). This indicates that when fat was replaced by SPE no significant energy compensation was found in a group that showed energy compensation when fat was replaced by water. The main difference between the SPE $\times$ fat-series and the fat-series was the level of greasiness. It could be that these differences in greasiness resulted in the differences found between the two series, although the effects of the SPE-series (with no differences in energy intake) do not support this.

The results of the women are in line with the studies of Glueck et al. (1982), Cotton et al. (1993) and Hulshof et al. (1993a, 1995), whereas the results of the men are more in line with those of Blundell et al. (1992) and Rolls et al. (1992). In the studies of Blundell et al. (1992) and Rolls et al. (1992) only men participated, as in the study of Cotton et al. (1993). In the studies of Hulshof et al. $(1993 a, 1995)$ both sexes were investigated, and in the study of Glueck et al. (1982) there were only seven women and three men. Therefore it is not clear if these differences are due to sex differences or due to differences in the methodological design.

It should be noted that although the 'appetite for a meal' ratings were low, a relatively large amount of food was consumed by the women at the test meal. This could be due to several factors. First, the subjects were obliged to come to the departmental dining room for the test meal, and this could be an extra motivation to eat. Secondly, their 'oversatiety (overfullness)' ratings were not high, being 4.7 and 7.8 units (out of the maximum value of 25) just before test-meal consumption. Although their appetite was not high, they were also not very full. The third reason is that the test meal was a snack meal. The mean of the individual correlations between 'appetite for a snack' $(r 0.38)$, 'appetite for something savoury' ( $r$ 0.28) and 'appetite for something sweet' ( $r 0.28)$ correlated higher with the subsequent energy intake at the test meal than 'appetite for a meal' $(r 0 \cdot 16)$, 'oversatiety (overfullness)' ( $r$ 0.23) and 'feeble, weak with hunger' $(r 0.14)$ in women.

\section{Plus v. minus manipulation of the preload}

According to the 1992 Dutch nutrition survey the average energy intakes at lunch were 1.9 and 2.9 MJ for women and men respectively (Voorlichtingsbureau voor de voeding, 1993). 
The three preload energy levels in the present study were on average $1.8,2.7$ and $3.7 \mathrm{MJ}$. For women the $1.8 \mathrm{MJ}$ preload was on average equal to their normal intake, the other two preloads were higher than their normal intake indicating on average a plus manipulation. In men, only the high-energy preload was higher than their normal intake, whereas the lowenergy preload resulted in a minus manipulation. It could be argued that the difference in manipulation (plus $v$. minus) between men and women was one of the causes for the different results between the sexes (Foltin et al. 1988; Mattes et al. 1988). Therefore the question arises whether the women would have shown energy compensation if the preloads had been a minus manipulation for them.

\section{Differences in energy intake between day 1 and day 2}

When the total energy intake of day 1 (with preload energy) was compared with the total energy intake of day 2 , large differences were found for both men and women in both studies. On day 1 significantly more energy was consumed in both studies compared with day 2 , by both men and women (3.7 and $1.8 \mathrm{MJ}$ respectively). These differences were mainly due to the relatively large preload + test-meal intake on day 1 compared with the more regular afternoon intake on day 2.

The methodological design with an attractive test-meal buffet at a snack moment seemed to increase the total energy intake of that day. However, the results of the men do not indicate that this methodological effect influences the ability of the subjects to compensate for the differences in the energy content between the preloads.

\section{Macronutrient intake}

As in other studies (Rolls et al. 1988, 1992; de Graaf et al. 1992; Hulshof et al. 1993a,1995), no macronutrient compensation occurred in the rice or macaroni studies in men or women. Subjects did not consume less fat after the high-fat preloads, nor did they eat more fat after the low-fat preloads. This means that, even when energy compensation is complete, the percentage energy derived from fat decreases when a fat replacer like SPE is used (Beaton et al. 1992).

\section{Cognition and duration of the manipulation}

In the present study only the short-term effects were investigated. This does not give an indication about the effects in the longer term. SPE will only be a useful aid to reduce fat and energy intake if in the longer term no full compensatory response of energy or fat intake occurs. In the only long-term study (20 d) with SPE (Glueck et al. 1982), no complete energy compensation was found, like the results of the women in the present study. However, more long-term studies on the effects of SPE as a fat replacer are required, as only seven obese women and three obese men participated in the study of Glueck $e t$ al. (1982). Because a long period consists of many short periods, it is obvious that the shortterm effects must influence the effects in the long term. At present it is unclear how shortterm influences on food intake affect food intake in the longer run. It is clear, however, that in the long run learning processes can occur (Louis-Sylvestre et al. 1989) that can influence the food intake processes (Kendall et al. 1991). These influences will not be found in shortterm experiments. Short-term studies can, however, be useful for generating hypotheses for longer term studies.

Another issue is the knowledge of the preload manipulation of the subjects. In the present study and in other studies on SPE (Glueck et al. 1982; Blundell et al. 1992; Rolls et al. 1992; Cotton et al. 1993; Hulshof et al. 1993a, 1995) the subjects were unaware of the preload manipulation. When SPE is used as a fat replacer in food products, awareness of 
the energy reduction in products with SPE will generally be the case. As cognition can influence feelings of appetite (Wooley et al. 1972), this has to be taken into account.

\section{Effects of differences in pleasantness and greasiness on appetite and energy intake}

In several studies the problem of differences of pleasantness affecting appetite and energy intake has been pointed out (Hill et al. 1984; Warwick et al. 1993). In the present study we had the opportunity to test the effects of differences in pleasantness and perceived greasiness on energy intake in the SPE series (i.e. SPE-, SPE/water- and the waterpreloads). In the SPE-series the energy levels of the preloads were constant, but there were significantly different pleasantness and perceived greasiness ratings between the three preloads.

No significant differences were found within the SPE series with respect to appetite or energy intake. The correlations between the pleasantness, or greasiness, of the products and the energy intake at the test meal, or the appetite ratings between the preload and the test meal, showed no relationship in men or women (all $r$ values between -0.04 and 0.09 , $P>0.21$ ). The only significant correlation found was in men between the pleasantness and 'appetite for a meal' ratings (AUC\%) with $r 0.21(P<0.002)$. These results indicate that differences in pleasantness or perceived greasiness of the preloads had no or minor effects on appetite, or the energy intake at a test meal $2 \mathrm{~h}$ later.

\section{CONCLUSIONS}

The present short-term studies indicate that the replacement of fat by SPE does not result in any differences in energy intake or appetite feelings in women. In men, also, no statistically significant energy compensation was found when fat was replaced by SPE. This was true for a population that did compensate when the energy differences in the preloads occurred without addition of the fat replacer SPE. The appetite feelings were in line with the differences in energy intake. The result was that in both men and women lower total energy intakes were obtained with the SPE-preloads compared with the fat-preloads. No macronutrient compensation occurred. This means that even when there is complete energy compensation the percentage energy derived from fat will still decrease when using a fat replacer like SPE.

We would like to thank Jolanda van Aert, Monique van den Broek, Monique Jegerings and Saskia Hahn for their assistance in data collection. The deep-frozen meals were donated by IGLO-OLA.

\section{REFERENCES}

Beaton, G. H., Tarasuk, V. \& Anderson, G. H. (1992). Estimation of possible impact of non-caloric fat and carbohydrate substitutes on macronutrient intake in the human. Appetite 43, 145-153.

Birch, L. L., Johnson, S. L., Jones, M. B. \& Peters, J. C. (1993). Effects of a nonenergy fat substitute on children's energy and macronutrient intake. American Journal of Clinical Nutrition 58, 326-333.

Blundell, J., Burley, V., Cotton, J. \& Lawton, C. (1992). Dietary fat and appetite control: weak effects on satiation (within-meals) and satiety (between meals). In Dietary Fats: Determinants of Preference, Selection and Consumption, pp. 79-101 [D. J. Mela, editor]. London and New York: Elsevier Applied Science.

Cameron, M. E. \& van Staveren, W. A. (1988). Manual on Methodology for Food Consumption Studies. Oxford: Oxford University Press

Cotton, J. R., Burley, V. J. \& Blundell, J. E. (1993). Effect on appetite of replacing natural fat with sucrose polyester in meals or snacks across one whole day. International Journal of Obesity 17, Suppl. 2, 47 Abstr.

de Graaf, C., Hulshof, A. F. J., Weststrate, J. A. \& Jas, P. (1992). Short-term effects of different amounts of protein, fats and carbohydrates on satiety. American Journal of Clinical Nutrition 55, 33-38.

Durnin, J. V. G. A. \& Womersley, J. (1974). Body fat assessed from total body density and its estimation from skinfolds thickness: measurements on 481 men and women aged from 16 to 72 years. British Journal of Nutrition 32, 77-97. 
Fallat, R. W., Glueck, C. J., Lutmer, R. \& Mattson, F. H. (1976). Short term study of sucrose polyester a nonabsorbable fat-like material as a dietary agent for lowering plasma cholesterol. American Journal of Clinical Nutrition 29, 1204-1215.

Foltin, R. W., Fischman, M. W., Emurian, C. S. \& Rachlinski, J. J. (1988). Compensation for caloric dilution in humans given unrestricted access to food in a residential laboratory. Appetite 10, 13-24.

Glueck, C. J., Hastings, M. M., Allen, R. D., Hogg, E., Baehler, L., Gartside, P. S., Phillips, D., Jones, M., Hollenbach, E. J., Braun, B. \& Anastasia, J. V. (1982). Sucrose polyester and covert caloric dilution. American Journal of Clinical Nutrition 35, 1352-1359.

Hill, A. J., Magson, L. D. \& Blundell, J. E. (1984). Hunger and palatability: tracking ratings of subjective experience before, during and after the consumption of preferred and less preferred food. Appetite 53A, 361-371.

Hulshof, T., de Graaf, C. \& Weststrate, J. A. (1993a). Fat and non-absorbable fat (SPE) in croissants have similar effects on satiety and subsequent short term food intake. International Journal of Obesity 17, Suppl. 2, 64 Abstr.

Hulshof, T., de Graaf, C. \& Weststrate, J. A. (1993b). The effects of preloads varying in physical state and fat content on satiety and energy intake. Appetite $21,273-286$.

Hulshof, T., de Graaf, C. \& Weststrate, J. A. (1995). Short-term effects of high-fat and low-fat/high SPE croissants on appetite and energy intake at three deprivation periods. Physiology \& Behavior 57, $377-383$.

Kendall, A., Levitsky, D. A., Strupp, B. J. \& Lissner, L. (1991). Weight loss on a low-fat diet: consequence of the imprecision of the control of food intake in humans. American Journal of Clinical Nutrition 53, 1124-1129.

Kissileff, H. R. (1984). Satiating efficiency and a strategy for conducting food loading experiments. Neuroscience and Biobehavorial Reviews 8, 129-135.

Louis-Sylvestre, J., Tournier, A., Verger, P., Chabert, M., Delorme, B. \& Hossenlopp, J. (1989). Learned caloric adjustment of human intake. Appetite 12, 95-103.

Mattes, R. D., Pierce, C. B. \& Friedman, M. I. (1988). Daily caloric intake of normal-weight adults: response to changes in dietary energy density of a luncheon meal. American Journal of Clinical Nutrition 48, 214219.

NEVO (1986). NEVO Dutch Nutrient Database. Zeist, The Netherlands: Stichting NEVO.

Rolls, B. J., Hetherington, M. \& Burley, V. J. (1988). The specificity of satiety: the influence of foods of different macronutrient content on the development of satiety. Physiology and Behavior 43, 145-153.

Rolls, B. J., Pirraglia, P. A., Jones, M. B. \& Peters, J. C. (1992). Effects of olestra, a noncaloric fat substitute, on daily energy and fat intakes in lean men. American Journal of Clinical Nutrition 56, 84-92.

Statistical Analysis Systems (1990). SAS-STAT User's Guide, version 6, 4th ed. Cary, NC: SAS Institute Inc.

van Strien, T. (1986). Eating behaviour, personality traits and body mass (Thesis). Lisse, The Netherlands: Swets \& Zeitlinger.

Voorlichtingsbureau voor de voeding (1993). Zo eet Nederland: The National Food Consumption Survey 1992. Den Haag: Voorlichtingsbureau.

Warwick, Z. S., Hall, W. G., Pappas, T. N. \& Schiffman, S. S. (1993). Taste and smell sensations enhance the satiating effect of both a high-carbohydrate and a high-fat meal in humans. Physiology and Behavior 53, 553-563.

Wooley, O. W., Wooley, S. C. \& Dunham, R. B. (1972). Can calories be perceived and do they affect hunger in obese and nonobese humans. Journal of Comparative and Physiological Psychology 80, 250-258. 
APPENDIX A

Energy content and the macronutrient composition of the products served in the buffet of the rice and the macaroni studies

\begin{tabular}{|c|c|c|c|c|}
\hline Product & $\begin{array}{l}\text { Fat } \\
\text { g/kg }\end{array}$ & $\begin{array}{c}\text { Protein } \\
\text { g/kg }\end{array}$ & $\begin{array}{c}\text { Carbohydrate } \\
\text { g/kg }\end{array}$ & $\begin{array}{c}\text { Energy } \\
\mathrm{kJ} / \mathbf{k g}\end{array}$ \\
\hline 1 Semi-skimmed milk & 20 & 40 & 50 & 2260 \\
\hline 2 Full-fat chocolate milk & 40 & 40 & 100 & 3850 \\
\hline 3 Drinking yoghurt & $\mathbf{0}$ & 30 & 133 & 2730 \\
\hline 4 Orange juice & $\mathbf{0}$ & 0 & 80 & 1340 \\
\hline 5 Curd with fruit flavour & 10 & 90 & 160 & 4560 \\
\hline 6 Whole-milk yoghurt & 20 & 30 & 160 & 3930 \\
\hline 7 Custard (whole milk) & 40 & 30 & 150 & 4520 \\
\hline 8 Apple with peel & 0 & 0 & 100 & 1670 \\
\hline 9 Orange & 0 & 0 & 100 & 1670 \\
\hline 10 Banana & 0 & 10 & 220 & 3850 \\
\hline 11 Apple pie & 254 & 60 & 537 & 19560 \\
\hline 12 Dutch treacle wafer & 280 & 50 & 520 & 20080 \\
\hline 13 Cake with almond filling & 240 & 50 & 480 & 17910 \\
\hline 14 Fancy iced cake & 134 & 34 & 611 & 15840 \\
\hline 15 Cake with apple filling & 171 & 108 & 612 & 18490 \\
\hline 16 Mars bar & 180 & 50 & 670 & 18830 \\
\hline 17 Snickers & 250 & 100 & 550 & 20290 \\
\hline 18 Twix & 250 & 60 & 620 & 20790 \\
\hline 19 Raisin roll & 30 & 70 & 500 & 10670 \\
\hline 20 White roll (ham) & 105 & 103 & 305 & 10780 \\
\hline 21 Brown roll (ham) & 92 & 103 & 279 & 9860 \\
\hline 22 White roll (cheese) & 176 & 126 & 302 & 13790 \\
\hline 23 Brown roll (cheese) & 164 & 126 & 276 & 12900 \\
\hline 24 Sausage roll & 300 & 110 & 330 & 18660 \\
\hline 25 Kroket* & 180 & 70 & 230 & 11800 \\
\hline 26 Fricandel* & 230 & 150 & 90 & 12680 \\
\hline 27 Potato crisp (natural) & 370 & 50 & 460 & 22470 \\
\hline 28 Potato crisp (paprika) & 370 & 50 & 460 & 22470 \\
\hline 29 Mayonnaise & 800 & 10 & 20 & 30630 \\
\hline 30 Mustard & 40 & 50 & 60 & 3350 \\
\hline 31 Tomato ketchup & 0 & 10 & 340 & 5860 \\
\hline
\end{tabular}

* Typical Dutch savoury snacks (kind of sausage roll). 